\title{
O DIREITO COMPARADO NA JURISDIÇÃO CONSTITUCIONAL
}

\author{
Gustavo Vitorino Cardoso
}

THE COMPARATIVE LAW IN THE CONSTITUTIONAL ADJUDICATION

\section{RESUMO}

ESTE ESTUDO ABORDA O CRESCENTE USO DO DIREITO COMPARADO NA RACIONALIDADE DAS DECISÕES DOS TRIBUNAIS CONSTITUCIONAIS. TEMA EXTREMAMENTE INTERESSANTE E ATUAL, A APROXIMAC̣ÃO DO DIREITO CONSTITUCIONAL AO DIREITO COMPARADO É ILUSTRADA A PARTIR de CASOS Julgados em PORTugal, Estados Unidos E ÁFRICA DO SUL E QUE RECEBERAM ATENÇÃO ESPECIAL DA DOUTRINA, DESTACANDO-SE, NOMEADAMENTE, OS CONTORNOS HISTÓRICOS E JURÍDICOS CARACTERIZADORES DESSES ORDENAMENTOS JURÍDICOS. O PRIMEIRO OBJETIVO PERFAZ A VERIFICAÇÃO DO ALINHAMENTO DO Supremo Tribunal Federal à tendênCIA COMPARATIVA, O QUE É FEITO MEDIANTE A ANÁLISE MATERIALMENTE DIRECIONADA DA SUA JURISPRUDÊNCIA COLHIDA NO SÍTIO OFICIAL. A SEGUNDA ETAPA TEM COMO ESCOPO UMA EXPLICAÇÃO POSSÍVEL PARA O PROBLEMA INTRÍNSECO À INTERPRETAÇÃO/CONCRETIZAÇÃO DE REGRAS E PRINCÍPIOS CONSTITUCIONAIS, LANC̣ADA NA FUNDAMENTACÃO DE UMA DECISÃO COM BASE EM ELEMENTOS APURADOS EM OUTRA ORDEM JURÍDICA, TAREFA ESSA QUE É LEVADA A EFEITO COM APOIO NA CARACTERIZAÇÃO DO DENOMINADO ESTADO CONSTITUCIONAL. TODAS AS ETAPAS CUMPREM A FUNÇÃO MAIS GERAL DE INDAGAÇÃO ACERCA DO PAPEL QUE A COMPARAÇÃO DE DIREITOS TEM ALCANÇADO NO CONSTITUCIONALISMO DO PRESENTE.

\section{PALAVRAS-CHAVE}

DIREITO CONSTITUCIONAL; DIREITO COMPARADO; ESTADO CONSTITUCIONAL; TRIBUNAIS CONSTITUCIONAIS; SUPREMO TRIBUNAL FEDERAL.

\section{ABSTRACT}

THIS STUDY ADDRESSES THE GROWING USE OF THE COMPARATIVE LAW PERSPECTIVE IN THE RATIONALITY OF DECISIONS AT CONSTITUTIONAL COURTS. A MUCH INTERESTING AND ACTUAL TENDENCY, THE CORRELATION BETWEEN COMPARATIVE LAW AND CONSTITUTIONAL LAW IS REVEALED By CASES DECIDED IN PORTUgal, United States and SOUth AFRICA, WHICH HAS GATHERED GREAT SCHOLARLY ATTENTION, WITH SPECIAL FOCUS IN THE HISTORICAL AND LEGAL CONTOURS OF THESE JURISDICTIONS. THE FIRST AIM IS TO EXAMINE THE ALIGNMENT OF THE BRAZILIAN FEDERAL SUPREME COURT TO THE COMPARATIVE TREND, WHICH IS CARRIED OUT BY JURISPRUDENCE ANALYSIS OF DOCUMENTS AVAILABLE ON THE OFFICIAL WEBSITE OF THE INSTITUTION. IN ADDITION, IT WAS CONCEIVED A POSSIBLE EXPLANATION FOR THE INTRINSIC PROBLEM OF THE INTERPRETATION/CONCRETIZATION OF CONSTITUTIONAL RULES AND PRINCIPLES BASED ON DATA GATHERED IN ANOTHER LEGAL ORDER, A TASK SUPPORTED BY THE SO CALLED CONSTITUTIONAL STATE. THIS APPROACH HAS IN MIND TO INQUIRY THE ACTUAL ROLE THAT THE COMPARISON OF RIGHTS HAS REACHED IN THE PRESENT CONSTITUTIONALISM.

\section{KEYWORDS}

CONSTITUTIONAL LAW; COMPARATIVE LAW; CONSTITUTIONAL STATE; CONSTITUTIONAL COURTS; BRAZILIAN FEDERAL SUPREME COURT.

\section{INTRODUÇÃO}

Não é recente o reconhecimento do intenso aproveitamento das utilidades fornecidas pelo direito comparado para fins teóricos ou eminentemente doutrinários, cuja 
consequência mais saudável foi e continua sendo o desenvolvimento de abordagens contextualizadas de problemas comuns a vários sistemas jurídicos. Mas se percebe uma mudança nos domínios da comparação: atualmente, a argumentação comparada faz-se presente na racionalidade das decisões dos tribunais superiores de vários países, notadamente daqueles tribunais que precipuamente devem zelar pelo texto constitucional, "nova" realidade essa que não deixa de originar indagações de várias ordens e acaba mesmo por convidar à reflexão. Afinal, se os textos constitucionais conformam parte primordial da ordem jurídica do Estado e da sociedade a que se referem, qual é o fundamento para se registrarem no bojo da fundamentação de uma sentença elementos apurados em outra(s) ordem(ns) jurídica(s) a respeito de uma questão constitucional? Estaria o Supremo Tribunal Federal brasileiro alinhado a essa tendência interpretativo-concretizadora? Qual é a função que a comparação jurídica tem logrado manter no constitucionalismo do presente? Essas são as principais questões a que nos propomos enfrentar.

No presente estudo, as respostas a essas indagações são perseguidas em um percurso de quatro etapas. Primeiro, são feitas algumas elucidações a respeito do direito comparado, a sua origem, o seu desenvolvimento e uma breve consubstanciação teórica, chegando-se à expressão "comparação de direitos" como melhor representante do seu propósito fundamental. Em seguida, procuramos ilustrar a realidade judicativo-constitucional de Portugal, Estados Unidos e África do Sul, através das decisões mais comentadas pela doutrina especializada. ${ }^{1}$ A jurisprudência do Supremo Tribunal Federal é discutida em seguida, para demonstrar que os ministros brasileiros também se voltam à tendência comparativa. Na busca do fundamento teórico para a virada rumo à comparação jurídica, apresentamos a teoria da Constituição como ciência da cultura do jurista alemão Peter Häberle, que inculca a noção da comparação jurídica como quinto elemento de interpretação-concretização constitucional. ${ }^{2}$

\section{BREVES ANOTAÇÕES SOBRE O DIREITO COMPARADO 3}

Entendido por parte da doutrina como evolução do processo sistêmico e resultante da Escola Histórico-evolutiva (MAXIMILIANO, 2003), o Direito comparado era visto como moderníssimo até meados do século passado, à altura do império da Escola da Exegese. Invocado prioritariamente no campo da hermenêutica e menos na organização jurídica, esse processo de interpretação se desenvolveu, especialmente, sobre as tramas do direito privado, ${ }^{4}$ por se mostrar mais próspero ao postulado de aplicação uniforme, de modo que os encantos do novo processo pareciam permitir um direito privado comum de toda a sociedade civilizada (MAXIMILIANO, 2003).

$\mathrm{Na}$ sua origem, via-se que os povos cultos da época em condições análogas de regime político, organização social e cultura serviam-se dos mesmos organismos para estabelecer a mesma função com vistas ao mesmo fim. Assim, a pretensão de 
impingir ao estudo do fenômeno jurídico um verdadeiro caráter científico fez que os jurisconsultos se ocupassem do direito comparado, diferenciando-o, outrossim, da simples "legislação comparada" (MAXIMILIANO, 2003, p. 109), que já era percebida, mas como algo menor do que a ciência completa que se pretendia com a comparação.

No seu desenvolvimento, a disciplina passou a desempenhar papel cultural de grande valia. O estudo dos "direitos estrangeiros" constituiu fonte inegável de enriquecimento cultural, com notória utilidade para o melhor conhecimento do direito nacional e para o seu aperfeiçoamento (DAVID, 1986). Notou-se que problemas e soluções de outros sistemas poderiam esclarecer as complicações domésticas. Assim:

[...] as vantagens que o direito comparado oferece podem, sucintamente, ser colocadas em três planos. O direito comparado é útil nas investigações históricas ou filosóficas referentes ao direito; é útil para conhecer melhor e aperfeiçoar o nosso direito nacional; é, finalmente, útil para compreender os povos estrangeiros e estabelecer um melhor regime para as relações da vida internacional. (p. 3)

Nesse contexto, a interdependência das nações e as mostras da solidariedade que envolve o gênero humano, tendo se convolado em fatos evidentes no mundo contemporâneo - o mundo agora como um só, sem o isolamento de outrora - acabaram por impor, tanto aos políticos quanto aos economistas e aos juristas, uma nova visão dos problemas que lhes dizem respeito (DAVID, 1986).

Entendida como verdadeira ciência ${ }^{5}$ ou ainda apenas como um método (CANOTILHO, 2003), o direito comparado passou a se identificar com a pesquisa de um modelo melhor, conduzida mediante a análise temporal e materialmente recortada do modelo estrangeiro, as suas semelhanças e dessemelhanças (DANTAS, 1997) e, assim, avessa à mera especulação pendente de objetivo acerca dos padrões jurídicos de diversos ordenamentos, o que constituiria puro empirismo ou um exercício erudito (SACCO, 2001). Enfim, a comparação voltou-se para problemas práticos.

A tendência que intentamos demonstrar a seguir é o intenso uso do direito comparado, pelos juízes constitucionais nacionais, como método de interpretaçãoconcretização (e de realização) constitucional, 6 fenômeno que se desenvolve em várias intensidades e compreende doutrina, legislação e decisões estrangeiras. É importante destacar que o recurso a elementos exógenos já existia, por exemplo, nas colônias. A novidade é que atualmente não mais se verifica a recepção, e sim o diálogo enriquecedor do próprio direito interno, em que se percebe que os juízes citam outros sistemas não só para preencher as lacunas ou para tratar de algo novo tal como era feito no período colonial, mas para "find out how other judges have responded when faced with a comparable issue" (SLAUGHTER, 2003, p. 197). 
A seguir, com a ressalva de que, para nós, a ideia perseguida pelo comumente denominado direito comparado é mais bem representada pela expressão "comparação de direitos" - já que a dialética almejada não ocorre somente a partir da norma em si, mas também em razão do substrato social, econômico e cultural no qual ela se aloca -, ilustraremos a matéria em foco a partir de estudos de juristas em torno da jurisdição constitucional de Portugal, dos Estados Unidos e da África do Sul e, por último, apresentaremos alguns casos julgados pelo Supremo Tribunal Federal brasileiro. ${ }^{7}$ Em seguida, demonstraremos a importância da abertura das possibilidades interpretativas no nível constitucional a partir das noções desenvolvidas por Peter Häberle e sua teoria da Constituição como ciência da cultura, tudo para chegarmos em condições de, ao final, identificar elementos importantes no tocante ao argumento comparado na atividade decisória própria dos tribunais constitucionais.

\section{O ARGUMENTO COMPARADO NA LAVRA DO TRIBUNAL CONSTITUCIONAL PORTUGUÊS}

Desde a sua institucionalização formal, ${ }^{8}$ o Tribunal Constitucional Português (TCP) sempre se posicionou numa linha favorável ao uso do argumento comparado, ${ }^{9}$ apesar de inexistir no ordenamento jurídico ${ }^{10}$ qualquer determinação legal nesse sentido. ${ }^{11}$ Isso se deu, em primeiro lugar, a fim de galgar legitimação material dentro do quadro de poderes e esquema judiciário no qual o TCP foi implantado, para o que contribuiu uma argumentação mais ampla e conexa com os avanços doutrinários. Ademais, em um contexto em que o controle de constitucionalidade das normas do tipo misto complexo (CANOTILHO, 2003) se revelou como fonte de conflitos entre as várias instâncias do Poder Judiciário, o recurso ao elemento comparado contribuiu para o reconhecimento da autoridade do próprio Tribunal em consolidação, bem como para evitar exageros de autorreferência em um país de pequenas extensões e de pouca idade na vida liberal-democrática.

A notável abertura do TCP verificada no plano interpretativo material externo não se limitou aos primeiros anos da sua existência, persistindo até a atualidade. O resultado foi a sua entrada na conjuntura de participação de Cortes constitucionais na construção de orientações comuns, tendencialmente universais, processo no qual o órgão judicial se torna, ao mesmo tempo, sujeito ativo e passivo, embora com desigualdades no fornecimento dos parâmetros. Além disso, a jurisprudência portuguesa afirma a comparação como um meio para melhor compreensão das questões e das normas em exame e também como caminho para aprimorar a qualidade das suas próprias decisões, mantendo especialmente normas constitucionais e supraconstitucionais de outros países europeus como sustentáculos de uma espécie de tertium comparationis. ${ }^{12}$

Se em um primeiro instante a análise jurisprudencial permite aduzir que as citações estrangeiras são empregadas mais como componente acessório do que como 
exigência de fundamentação das decisões, verifica-se que em algumas decisões o Direito comparado é levado em conta inclusive na parte conclusiva da sentença. ${ }^{13}$ Tanto é verdade que, em decisão recente, o dado comparado surgiu como importante para a afirmação de que a norma portuguesa referente ao direito à revisão de sentenças não gozava de "fundamento suficientemente relevante na óptica constitucional para a solução normativa impugnada", ${ }^{14}$ obrigando a norma impugnada a ceder diante do resultado da interpretação comparada.

O TCP privilegia a comparação dos sistemas jurídicos tidos como próximos, eminentemente o alemão, muito em razão do reconhecimento de uma sobreposição substancial entre os ordenamentos. ${ }^{15}$ Os sistemas jurídicos mais citados são o alemão, o espanhol, o italiano, o norte-americano, o francês, o belga, o austríaco, o inglês e, finalmente, por razões histórico-culturais, o brasileiro (ORRÚ, 2006), ${ }^{16}$ sendo que os quatro primeiros são mais seguidos em termos de justiça constitucional.

Finalmente, o firme propósito do TCP em utilizar o argumento comparado é acompanhado do uso também constante do direito internacional, especialmente a Declaração dos Direitos do Homem e do Cidadão, estabelecendo, mormente nos julgados mais recentes, relações firmes com as sentenças proferidas pela Corte de Estrasburgo, que opera no âmbito da CEDU, de modo a quase fixar um ponto de referência irrenunciável e que acaba por demonstrar a inclinação pluralista dos juízes da Corte portuguesa (ORRÚ, 2006). ${ }^{17}$

\section{O DIREITO COMPARADO NA SUPREMA CORTE DOS ESTADOS UNIDOS}

Nos Estados Unidos, país marcado por uma forte tradição jurisprudencial sempre mais próxima do unilateralismo de suas próprias fórmulas jurídicas e com alta valorização dos precedentes jurisprudenciais, os métodos de trabalho da Corte Suprema parecem ter sofrido as consequências do contexto da afirmação plena do modelo político, econômico e cultural hasteado pelo país e que culminou na globalização, de modo que parte dos justices passou a empregar nas suas decisões fontes jurisprudenciais estrangeiras, embora de forma esporádica e intermitente, geralmente de países europeus ou de Estados partidários do sistema da Common Law (FERRARI, 2006).

Ainda que ao alvedrio de qualquer determinação legal no tocante ao uso da comparação, a abertura aos materiais externos se aprofundou sensivelmente a partir do fim do século XX e início do século atual, ${ }^{18}$ especialmente em temas como a moral sexual e a pena capital, mas sempre destinada ao combate de alguns componentes da própria Corte. É paradigmático a esse respeito o caso "Printz versus Estados Unidos", 19 de 1997, no qual se discutiu a constitucionalidade do "Brady Handgun Violence Prevention Act", que instituiu um sistema nacional de controle de armas de fogo. Contraditado a respeito da sua compatibilidade com o federalismo e a vontade dos founding fathers, manifestou-se no caso o juiz Stephen Breyer, ${ }^{20}$ que também em nome do juiz Stevens 
suscitou o federalismo suíço e alemão, bem como a própria experiência europeia, recordando sempre que ele estava consciente de que o objeto de interpretação era a Constituição norte-americana, mas que a comparação se fazia importante para abrir o leque de possibilidades de soluções a problemas comuns. Tal posicionamento sofreu duras críticas do juiz Antonin Scalia, com sua "nationalist jurisprudence" (FERRARI, 2006, p. 322), sob o argumento de que a comparação seria importante apenas no momento de redigir a Constituição, jamais na sua interpretação.

Mas já antes a comparação de direitos havia alçado lugar de destaque no judiciário constitucional norte-americano, na época do chamado "constitucionalismo repulsivo" ("aversive constitutionalism”). ${ }^{21}$ Nas décadas de 1940 e 1950 , o país foi diretamente confrontado às teorias e práticas da Alemanha nazista e da União Soviética. Assim, o anseio voluntarista de articular normas capazes de frontalmente distinguir os usos e as práticas do país daqueles modelos totalitaristas em voga na Europa contribuiu para um longo percurso liberal da Suprema Corte, o que ajudou a fortalecer, inclusive, os direitos e as liberdades civis, mormente no campo penal.

A história constitucional estadunidense recente remete também ao caso "Roper versus Simons”, ${ }^{22}$ de 2005. A sentença proibiu a pena capital aos menores de 18 anos, com fulcro na maturação da noção dos "standards of decency", presente na sociedade norte-americana, nas literaturas psicológica e criminológica, estas a demonstravam a ineficácia da medida. Ocorre que foram jungidas à decisão inúmeras legislações e jurisprudência estrangeiras, bem como normas de direito internacional, com o fito de demonstrar que a prática não se coadunava com a experiência comum no mundo, bem como que ela se mostrava contrária aos próprios valores culturais nacionais. Novamente, o juiz Scalia reagiu contrariamente ao manejo de argumentos comparados, por entender que tal argumentação estava sendo utilizada para colocar de lado as práticas difusas na história do país.

O interessante é notar que a adoção dessa metódica suscitou reações tanto negativas quanto positivas. Aquelas ensejaram a reprimenda de congressistas que propuseram leis contra o manejo do direito estrangeiro nas sentenças. ${ }^{23}$ A recepção positiva deu-se eminentemente na doutrina, do que são exemplares as teorizações de Ackerman (1997) acerca do "world constitucionalism"; de Tushnet (1999) sobre as possibilidades do constitucionalismo comparado; de Harold Koh (2004) sobre "community standards"; e, finalmente, de Anne-Marie Slaughter (2003) sobre a "global community of courts".

\section{O ARGUMENTO COMPARADO NA PRÁTICA DA CORTE CONSTITUCIONAL SUL-AFRICANA}

Examinando a realidade jurídica do maior país do continente africano, Rinella (2006) mostra que o uso do direito comparado pelos juízes da Corte constitucional possui legitimação expressa em razão do artigo 39, 1, ${ }^{24}$ da Constituição da República da 
África do Sul de 1996, o que alça a comparação jurídica à condição de instrumento de interpretação e concretização da carta de direitos e das liberdades fundamentais. Naquele país, os juízes promovem especialmente a comparação com os ordenamentos jurídicos que serviram de fonte para os textos constitucionais recentes (a Constituição provisória de 1993-1994 e a atual, acima referida). Rinella aduz que em algumas decisões não se faz possível distinguir quando a abordagem se dá com foco nas leis estrangeiras ou casos estrangeiros, o que permite aos magistrados se moverem sabiamente entre o "Law in the books" e o "Law in action".

É ilustrativa a sentença do caso "Zuma versus Estado”, a primeira a tratar da interpretação do texto constitucional provisório e que versou sobre a distribuição do ônus de provar a espontaneidade de uma confissão nos termos da lei processual penal em face da presunção de inocência estatuída pelo regramento constitucional, na qual já se sentiu forte influência do direito canadense tanto no estudo técnico (two stages, balanceamento) quanto na metódica da interpretação constitucional. ${ }^{25}$ É válida também a referência ao caso "Makwanyane", julgado em 1995, em que se controverteu a inconstitucionalidade da pena de morte e fez que o Tribunal analisasse o catálogo de direitos e liberdades, a pena de morte e a cláusula de limitação dos direitos a partir de vários outros ordenamentos jurídicos. Em suma, pode-se afirmar que as principais fontes de comparação se referem aos sistemas jurídicos canadense, norteamericano e alemão, preponderando a utilização racional e equilibrada do argumento comparado, sem vinculação da ratio decidendi. ${ }^{26}$

É importante observar que a África do Sul, país de língua inglesa e que tem experimentado nos últimos anos, desde que se soltou dos grilhões do apartheid, uma fase de profunda transição rumo à abertura democrática, fomentada também por uma renovação de seus quadros judicantes, ${ }^{27}$ apegou-se às experiências jurídico-constitucionais de Estados de cultural ocidental, de tradição democrática e vigilantes na proteção efetiva dos direitos fundamentais, adotando nomeadamente o modelo alemão da Grundgestz (RINELLA, 2006), mas o fez sem perder de vista as suas especificidades internas, uma autolimitação forjada pelos próprios magistrados diante da norma constitucional que apenas lhes faculta o manejo de material externo. ${ }^{28}$

Também se percebe que a comparação, além de contar com a inédita permissividade legal já referida, possui em seu favor a própria formação cultural e científica dos juízes, ${ }^{29}$ o que faz Rinella (2006) considerar a possibilidade de que a formação dos membros do Tribunal os tornou mais propensos a considerar o direito de outras jurisdições na construção da própria Constituição.

\section{O USO DA COMPARAÇÃO DE DIREITOS PELO SUPREMO TRIBUNAL FEDERAL} A análise da jurisprudência do Supremo Tribunal Federal ${ }^{30}$ permite afiançar que o direito comparado é manejado pelos ministros, volvendo-se como instrumento 
enriquecedor das decisões, embora ele não seja decisivo na formação da jurisprudência, e, assim como se dá nos Estados ditos "constitucionais" da atualidade, à exceção da África do Sul, como visto acima, não exista qualquer regramento, seja legal ou regimental, para o exercício da comparação pela Corte, fato que não tem impedido a consciente articulação da realidade dos casos com os direitos estrangeiros.

Tanto a doutrina como a jurisprudência de outros países são constantemente invocadas nos votos proferidos pelos ministros da Corte Suprema brasileira, principalmente os votos exarados pelos ministros Gilmar Ferreira Mendes, Celso de Mello, Joaquim Barbosa, Ellen Gracie e Eros Grau, ${ }^{31}$ que o fazem como forma de qualificação do debate e de aprofundamento das análises e argumentações desenvolvidas nos julgamentos, elidindo que o uso da comparação seja considerado mera citação decorativa. O resultado pode ser observado em decisões interessantemente fundamentadas e ricas culturalmente, alcançando, por conseguinte, a própria melhora da jurisprudência interna.

O STF mantém em seu sítio na rede mundial de computadores uma área específica destinada à publicação das traduções, nas línguas inglesa e espanhola, de resumos da sua jurisprudência mais significativa, o que tem o condão de promover o intercâmbio de informações legislativas e jurisprudenciais entre os diversos países. Ademais, é nesses casos mais significativos, entendidos aqui como polêmicos, ${ }^{32}$ que o direito comparado é mais habitualmente empregado. Não se trata de fenômeno muito recente no Tribunal, tendo crescido nos últimos anos o número de decisões que trazem a comparação no seu bojo. ${ }^{33}$

Recentemente, por ocasião da discussão do exercício do direito de greve por parte dos servidores públicos civis, ${ }^{34}$ o argumento comparado ajudou a garantir a evolução do tema na jurisprudência do Tribunal, tanto que o ministro e relator para o caso, Gilmar Ferreira Mendes, fez constar da ementa do acórdão que:

[n]a experiência do direito comparado (em especial, na Alemanha e na Itália), admite-se que o Poder Judiciário adote medidas normativas como alternativa legítima de superação de omissões inconstitucionais, sem que a proteção judicial efetiva a direitos fundamentais se configure como ofensa ao modelo de separação de poderes (CF, art. $2^{\circ}$ ).

O recurso ao argumento comparado mostrou que a experiência alemã sobre a declaração de inconstitucionalidade sem pronúncia de nulidade, tendo em vista especialmente as omissões legislativas parciais, assim como as sentenças aditivas do direito italiano, denotava que, em se tratando do direito de greve dos servidores públicos civis, estava-se diante de hipótese na qual a omissão constitucional reclamaria uma solução diferenciada.

No voto que proferiu, o ministro Celso de Mello teve oportunidade de destacar os modelos normativos do direito de greve dos servidores públicos no âmbito 
comparado, demonstrando, com tal exposição, o gritante e injustificado atraso do legislador brasileiro no concretizar da norma constitucional.

Outro caso de grande importância para o constitucionalismo brasileiro e no qual a comparação de direitos ganhou relevância foi o que discutiu a condenação do escritor e sócio de editora por delito de descriminação contra os judeus por ter publicado, distribuído e vendido ao público obras antissemitas, delito ao qual foi atribuída a imprescritibilidade prevista no artigo $5^{\circ}$, XLII, da Constituição Federal. ${ }^{35}$

$\mathrm{Na}$ decisão do caso, a extensa referência a instrumentos internacionais, especialmente a Declaração Universal dos Direitos Humanos, foi acompanhada da comparação jurídica mediante a análise e a articulação da lei francesa n ${ }^{\circ}$ 90.615/90; do artigo 416 do Novo Código Penal da França; da lei espanhola contra o racismo de 1995; do artigo 240 do Código Penal português; da Lei Gaysott, da França, de 1990; do "Licensing Act”, da Inglaterra, de 1695; da Emenda nº 1 da Constituição Americana de 1787; da "Race Relations Act”, de 1976. Também houve o registro de inúmeras decisões estrangeiras: os casos "Estados Unidos versus Lemrick Nelson", da Corte de Apelação da Califórnia, de agosto de 1999; "Mandla e outro versus Dowell Lee e outro", da Câmara dos Lords, na Inglaterra, de 1983; "Shaare Tefila Congregation versus Cobb" (US 615), da Suprema Corte norte-americana, de 1987; "Lüth", da Corte Constitucional Alemã (BverfGE 7, 198), julgado em 15 de janeiro de 1958; "Livro sobre a Guerra”, da Corte Constitucional Alemã (BverfGE 90, 1-22), julgado em 11 de janeiro de 1994; "Soldados assassinos", da Corte Constitucional alemã (BverfGE 93, 266-312), julgado em 10 de outubro de 1995; "Romance Pornográfico", também da Corte Constitucional alemã (BverfGE 83, 130), julgado em 27 de novembro de 1990; “Terminiello versus Chicago" (337 US 1), da Suprema Corte norte-americana, julgado em 16 de maio de 1949; "R.A.V. versus City of St. Paul” (505 US 377), da Suprema Corte, julgado em 22 de junho de 1992; "Texas versus Johnson” (491 U.S. 397), também da Suprema Corte norte-americana, julgado em 21 de junho de 1989; "Publicação cômica contra o povo judeu”, julgado pelo Tribunal Constitucional espanhol, sentença 176/1995, de 1995; "Schenck versus United States" (249 U.S. 47, 52), com o voto do Juiz Oliver Wendell Holmes Jr., proferido em 1919; "Virginia versus Black et al.”, da Suprema Corte dos Estados Unidos; e, finalmente, o caso "Jersild versus Dinamarca", julgado pela Corte Europeia de Direitos Humanos em setembro de 1994. ${ }^{36}$

Na Questão de Ordem na Arguição de Descumprimento de Preceito Fundamental $n^{\circ}$ 54/DF, novamente através da lavra do ministro Gilmar Ferreira Mendes, ponderou-se a respeito da "Roe versus Wade", da Suprema Corte dos Estados Unidos; de inúmeras decisões da Corte alemã e da Corte Constitucional italiana; da Constituição de Weimar; dos artigos 123, inciso I, e 178, inciso II, da Constituição de Bonn; do artigo 282, parágrafo $4^{\circ}$, da Constituição portuguesa de 1976; dos artigos 33, e 44, I, “A”, da Lei Orgânica do Tribunal Constitucional espanhol; do artigo 44, parágrafo 90, incisos I e II, da Lei Orgânica da Corte Constitucional alemã; do 
capítulo 3, artigos 2213-1 a 2213-4, do livro 2 do Código de Saúde Pública da França; do artigo 140 da Lei Constitucional da Áustria; do artigo 134 da Constituição da Itália; e da Lei Constitucional de 9 de fevereiro de 1948, da Itália.

Todo esse esforço se deu, em parte, para demonstrar que a maior parte dos Estados constitucionais assegurava aos seus respectivos tribunais constitucionais competência para aferir a constitucionalidade das leis pré-constitucionais em face da Constituição vigente e, também, para reprochar uma introdução acrítica no ordenamento brasileiro da cláusula de subsidiariedade na forma como existe no direito alemão (recurso constitucional) e no direito espanhol (recurso de amparo), para fins de admissibilidade da arguição de preceito fundamental nos termos da Lei $\mathrm{n}^{\circ}$ 9.882/99.

No mesmo caso, a ministra Ellen Gracie frisou o valor da comparação jurídica por se estar diante de um instituto novo, em boa parte influenciado pela experiência constitucional europeia, enquanto o ministro Carlos Veloso citou apenas a legislação francesa para demonstrar a complexidade do caso submetido à apreciação do STF.

A habitualidade com que o STF se mune da comparação não é, atualmente, confrontada pelos juristas atentos aos trabalhos do Tribunal. No tocante à doutrina, é importante frisar o constante uso de estudos estrangeiros nas decisões da Corte brasileira, especialmente os provenientes da ciência jurídica espanhola, alemã, italiana e francesa. ${ }^{37-38}$

Pode-se, assim, afirmar que o argumento comparado não é de modo algum ignorado pela prática judicativa. Pelo contrário, pois é explorado a fundo pelos juízes constitucionais de vários países, tendência da qual os juízes do STF não se afastam, ainda que neste a comparação não seja de fundo, isto é, não venha acompanhada da discussão sobre os alicerces contextuais da lei, do precedente ou da doutrina estrangeira. Respondida positivamente a pergunta acerca da disposição brasileira à comparação jurídica em sede constitucional, resta-nos aprofundar no exame dela e perscrutar um fundamento hábil para que se justifique o registro e a articulação, no bojo da fundamentação de uma sentença, de elementos de outras ordens jurídicas a respeito de uma questão constitucional.

\section{UM FUNDAMENTO POSSÍVEL: A ABERTURA DE POSSIBILIDADES E O DIREITO COMPARADO COMO QUINTO ELEMENTO DE INTERPRETAÇÃO CONSTITUCIONAL. A TEORIA DA CONSTITUIÇÃO COMO CIÊNCIA DA CULTURA}

Antagonicamente, exige-se que a Constituição de um país se valha concomitantemente de duas pretensões: de estabilidade e de dinamicidade (CANOTILHO, 2003, p. 1.435). ${ }^{39}$ Entretanto, tal antagonismo dilui-se à medida que se percebe que ele é apenas aparente, porquanto é muito desejável que a Constituição, na sua condição de ordem jurídica fundamental do Estado e da sociedade (HÄBERLE, 2003, p. 165), ofereça-se tanto à rigidez naquilo que a estrutura - a fim de garantir já aqui a sua 
sobrevivência -, quanto à abertura ao futuro e às inevitáveis movimentações sociais, políticas e culturais - coroando o seu movimento de autoconservação.

Nessa sua condição de ordem aberta ${ }^{40}$ é que assenta a noção da Constituição como ordem-quadro, de característica notadamente não exaustiva (CANOTILHO, 2003, p. 1.436), desenvolvida mediante processo público em uma sociedade aberta e favorável ao pluralismo social, econômico e político, tendo diante de si - e com a tarefa de assimilá-los - os fenômenos organizativos supranacionais, bem como a própria globalização, econômica e jurídica, aos quais se acrescenta a pluralidade cultural interna.

Nessa mesma senda, sabe-se que preceitos constitucionais, ainda que escritos em idênticos termos, não necessariamente têm o mesmo significado, variando tanto em razão do tempo quanto do espaço. A cultura parece ser, portanto, o elemento que explica essa variação. Por outro lado, as contribuições de cada comunidade, em cada etapa histórica, tendem a incorporar-se à cultura compartilhada, sem prejuízo de que cada conjunto social no exercício de interiorização das experiências exteriores o faça incluindo os seus próprios elementos específicos, gerando, com isso, novidades as quais se incorporam ao intercâmbio crescente de padrões culturais, o que torna os Estados constitucionais cada vez mais homogêneos e codeterminados, de maneira que eles podem ser concebidos como um produto multicultural (VALADÉS, 2003, p. xxxvi). Nesse diapasão, a cultura pode ser observada como verdadeiro fator constitutivo da Constituição (ZAGREBELSKY, 2006, p. 370).

Ademais, não se pode perder de vista que, segundo Häberle (apud MENDES, 2009) "es gibt keine Rechtsnormen, es gibt nur interpretierte Rechtsnormen. Interpretar um ato normativo nada mais é do que colocá-lo no tempo ou integrá-lo na realidade pública”. ${ }^{41}$ Daí decorre a importância de melhorar a interpretação jurídica como elemento constitutivo da própria concretização constitucional.

E, por estarem os juízes vinculados a essa ordem viva, acreditamos que a função deles, especialmente daqueles que ocupam as posições cimeiras dos sistemas jurisdicionais dos países, é decisiva e preponderante para o reclamado processo de interpretação e densificação de regras e princípios constitucionais, bem como da própria evolução constitucional, o que pode ser levado a efeito especialmente através do direito comparado. De fato, independente do sistema invocado, compete ao Judiciário a função de intérprete supremo da Constituição (MAXIMILIANO, 2003, p. 255).

A leitura atenta da jurisprudência estrangeira confirma que os juízes nacionais têm, de fato, deixado de afivelar as máscaras de meros aplicadores da lei para se tornarem guias da dinamização da Constituição, dado que eles conservam na atualidade a última palavra em matéria de interpretação (COELHO, 1998, p. 188). A crise do constitucionalismo, na qual também se verifica uma relativização do estatismo em matéria de fontes do direito (HÄBERLE, 2003, p.128), lança luzes sobre a atuação 
jurisdicional-constitucional em um tipo de Estado constitucional cultural cuja arma mais disseminada está a ser o direito comparado, em razão da sua vocação ao estabelecimento de comunicação entre as várias Constituições e à melhor apuração da decisão para o caso concreto (CANOTILHO, 2003, p. 1.214).

Para viabilizar a ideia de um Estado constitucional cultural, Häberle propõe, no que é apoiado por Pablo Lucas Verdú (1998), uma teoria da Constituição como ciência da cultura. É o próprio jurista alemão quem condensa em dez teses as ideias apresentadas em seu livro, cujo objetivo é apresentar as diretrizes para uma teoria constitucional apoiada na cultura (HÄBERLE, 2000).

A teoria da Constituição como ciência da cultura possui o mérito de primeiro ter compreendido a necessidade de pôr em causa os métodos tradicionais de estudo do direito constitucional, fomentando a necessidade de uma análise realista do novo papel dos juristas na sociedade contemporânea, globalizada, em particular a importância da jurisprudência dos tribunais constitucionais e dos processos de integração. A disciplina como produto da cultura característica de uma era se faz compreensível como "parte de la cultura" (HÄBERLE, 2003, p. 21), deixando no passado o seu entendimento como uma disciplina puramente técnica, o que permite identificar um novo modelo de Estado constitucional, diferente do Estado liberal do século XIX. Desafivelando-se do tecnicismo de outrora, a teoria da Constituição como ciência da cultura destaca métodos e princípios que se encontram em clara oposição ao conceito que considera a lei constitucional como voltada, sobretudo, para o estudo da hierarquia das fontes e para a reconstrução voluntarista da lei constitucional. A teoria cultural traz em consideração a evolução atual das Constituições liberais-democráticas (não apenas as europeias), observando os níveis textuais no sentido estrito (ou seja, as disposições das Constituições diferentes em vigor), mas sem olvidar da análise de tais sistemas em todas as manifestações da cultura, incluindo a filosofia, a literatura e a arte.

Abrem-se os critérios de interpretação, o que ocorre, na proposta de Häberle, à medida que a sociedade se mostra pluralista, negando a existência de numerus clausus de intérpretes constitucionais (HÄBERLE, 2003, p. 150), diante do que se afirma que, no atual estágio de desenvolvimento de muitos sistemas jurídicos nos quais se verificam sociedades abertas de intérpretes constitucionais, as Constituições representam o saldo de um processo plural, que não termina com a sessão de encerramento da Assembleia Constituinte, mas permanece constantemente aberto.

Segundo essa concepção, o círculo de intérpretes da Constituição deve ser amplo, com o fim de abarcar não somente as autoridades públicas e os intérpretes formais nos processos de controle de constitucionalidade, mas todos os cidadãos e grupos sociais que de uma ou outra forma vivem a realidade constitucional (MENDES, 2009, p. 67). É por isso que afirma Häberle (2003, p. 150): "quien vive la norma, también la interpreta". 
Häberle (2003, p. 124) ressalta que na sociedade aberta de intérpretes da Constituição não é necessário enfatizar a noção dogmática de "fonte de direito", por referir-se esta unicamente ao nível textual, devendo ser considerados todos os demais elementos que contribuem para a compreensão do desenvolvimento do direito constitucional contemporâneo, proporcionando um significado adequado aos diversos fenômenos concorrentes no processo de concretização constitucional, carecendo destacar o recurso aos clássicos considerados em seus contextos ${ }^{42}$ e a referência às mesmas noções na memória dos constituintes e dos intérpretes da Constituição.

Ao adotar a visão de que o direito constitucional possui natureza não técnica, mas intimamente cultural, torna-se necessário destacar ser essa verdadeiramente uma escolha metodológica no estudo da disciplina. Häberle propõe, de fato, um uso mais significativo de textos e de seu conteúdo valorativo, a fim de compreender a dinâmica do direito vivo. Mas o autor considera ser preciso romper com os conceitos tradicionais com os quais a doutrina tem abordado os textos constitucionais. Os cânones de interpretação não devem ser manejados como uma técnica para buscar a vontade do constituinte, mas para fazer emergir conceitos de avaliação e as orientações culturais que se afirmam na sociedade contemporânea e que constituem a base de toda a legislação constitucional existente. Assim, a cultura revela-se na essência do direito constitucional e da Constituição, devendo esta, portanto, ser vista como uma expressão do estado cultural de um povo. Assim vistas as coisas, é óbvio que a Constituição não pode ser identificada mais como um ato estatal somente. As Constituições escritas revelam-se níveis textuais da cultura constitucional, com a consideração de ser a autêntica Constituição a Constituição viva.

A Constituição do Estado constitucional convola-se, assim, em uma Constituição integrada por numerosos elementos, sobrepondo-se a todos a dimensão cultural, atingindo até mesmo a tradicional doutrina acerca dos elementos do Estado.

Da leitura da doutrina que estabelece a noção cultural da Constituição, percebese o apreço por todas as culturas do planeta, não sendo ela de modo algum limitada às experiências constitucionais europeias, deixando transparecer uma preferência pela cultura política liberal-democrática que se funda sobre uma vinculação aos pressupostos valorativos e culturais da filosofia política ocidental, especialmente a alemã e em parte a norte-americana, assim como pelos clássicos que se aprofundaram nos valores culturais. Essa opção permite compreender o conteúdo do modelo de Estado constitucional que remete os juristas contemporâneos ao projeto de futuro para o mundo. Este seria um modelo em que concorreriam um elemento normativo, no sentido de um dever-ser que exige primeiramente a manutenção de algumas das realizações da cultura jurídica e política ocidentais, um elemento realista, em que se consideram as condições objetivas que limitam as ações dos protagonistas do direito constitucional, e, finalmente, um terceiro elemento, representado por aquilo que Häberle (2003, p. 301) chama de "pensamento das possibilidades". 
Este último, representativo de um pensamento constantemente aberto a alternativas, parece ser o mais significativo para a compreensão de todo o conceito de Constituição aberta. Trata-se de um elemento que remete à mesma noção de uma cultura jurídica que assume o pluralismo como princípio fundamental da ordem constitucional e ajuda a entender a normatividade constitucional a partir de um processo dialético de contínua transformação do direito constitucional, o qual permite à normalidade - realidade - se converter em normatividade e permite à norma se volver em normalidade.

Compreende-se, portanto, haver na teoria da Constituição como ciência da cultura um otimismo evolutivo acerca do direito constitucional, pautado na promessa de uma expansão gradual do modelo de Estado constitucional a partir da convicção de que tal modelo oferece uma noção mais aberta e pluralista da cultura constitucional, inspirado sempre por um reconhecimento da dignidade humana.

Importa sublinhar que tal concepção oferece uma leitura da experiência constitucional contemporânea em moldes não formalistas, subvertendo a tradicional primazia do Estado sobre a Constituição, atenta aos conteúdos valorativos dos desenvolvimentos mais atuais da disciplina, dando azo a reflexões sobre a cultura e a história constitucional sem pretensão de servir como condicionante dogmático, sendo ela verdadeiramente aberta ao futuro.

Vista a cultura como fator essencial para compreensão das experiências constitucionais, abre-se também o espaço para uma nova análise dos níveis textuais, agora de uma forma diferente daquela experimentada pela exegese positivista. $\mathrm{Na}$ teoria cultural, mostra-se imprescindível a consciência da importância da cultura para o direito constitucional, consciência essa que impede que se veja nos textos a única e verdadeira fonte de direito, garantindo menos rigidez e mais flexibilidade no trato constitucional, tudo como resultado da sociedade aberta de intérpretes constitucionais, na qual todas as opiniões, todas as correntes jurídicas (mesmo as das minorias) possuem significado jurídico. É por isso que a preferência é pela utilização da expressão fontes de direito pontuada por interrogações e entre comillas (HÄBERLE, 2003). ${ }^{43}$

Igualmente importante para a compreensão do novo tipo de Estado constitucional pluralista, a abertura às alternativas pressupõe um modo diverso de pensar a lógica jurídica e a argumentação. O pensamento das possibilidades se baseia na abertura às alternativas, ao que se opõe a lógica de um dever-ser absoluto: a dúvida é bem-vinda, favorece a possibilidade de pensar em função de alternativas contrárias a qualquer absolutismo e sempre aceita a possibilidade do "outro". A consideração da alternativa deve ser real, o que exige do Estado constitucional o fornecimento de meios procedimentais para tanto.

Essa ideia da Constituição como realidade complexa, como processo aberto que se desenvolve em múltiplos níveis e garantidor da participação de um número cada 
vez maior de pessoas, unida à convicção de que nenhuma ordem constitucional pode ser concebida hoje como uma estrutura fechada ao exterior, implica em alterações no próprio método de estudo da disciplina. Para tanto, o direito comparado aparece com toda a força para o estudo dos diferentes ordenamentos jurídicos, a fim de possibilitar a compreensão das diversas experiências jurídicas, fazendo ascender a imagem das trocas culturais e mudanças sociais no mundo contemporâneo.

O direito comparado aparece, assim, com mais importância do que a construção de um sistema jurídico geral de conceitos jurídicos o qual busque fornecer valores cuja essencialidade seja intangível, mormente quando se verifica que somente através da comparação e da análise histórica dos diversos valores constitucionais é que se alcança uma consciência da essencialidade. Com efeito, cotejar as experiências jurídicas no espaço é também uma maneira de pensar sobre o direito que se caracteriza por se manter aberto às alternativas, que não considera a ciência jurídica como um conjunto compacto de questões a propósito da vontade do legislador de um único país.

Com base nesse método interpretativo, Häberle insere nas suas construções a comparação dos textos normativos e apresenta indícios de um processo mais profundo de difusão da cultura constitucional e de alguns modelos constitucionais, mostrando também que a mera comparação de textos é ineficiente, clamando a imprescindibilidade de que se alcance uma fase ulterior de comparação constitucional substancial: os contextos culturais, o que permite ao autor designar a sua teorização como "ciência jurídica dos textos e da cultura" (HÄBERLE, 2003, p. 83).

$\mathrm{Na}$ sua obra, Häberle aprecia especialmente a riqueza das formas dos textos constitucionais, a multiplicidade das possíveis Constituições, a sua complexidade, inclusive a linguística e variedade de funções, insistindo em explicar o seu próprio método de estudo por não ignorar os riscos de que seu pensamento se alie a uma leitura com ares dogmáticos. Antes de tudo, o método comparado no Estado constitucional convida à reflexão sobre a diversidade dos sistemas jurídicos e o significado das experiências jurídicas, confrontando-os entre si, assim como intenta aprofundar a análise nos diversos contextos culturais como pano de fundo para a descoberta da razão das mutações que sofrem as instituições (tanto no espaço quanto no tempo), reagindo ao desafio da proposição de uma Constituição que seja modelo único e universal.

A consideração do método comparado como quinto elemento de interpretação no Estado constitucional como marco metodológico se deve à conclusão de que aquele se apresenta como a via mediante a qual as diversas Constituições podem comunicar entre si, possibilitando que se adquira para cada uma e todas elas uma maior eficácia, em virtude da conformação do Estado constitucional (FERNANDÉZ SEGADO, 2003, p. XLIII).

Bem se vê, portanto, que a doutrina da teoria da Constituição com fulcro na ciência da cultura, para além de propor a teoria que embasa o seu pensamento, também 
se preocupa com o procedimento que viabiliza a prática das suas postulações teóricas, oferecendo, com isso, não apenas o caminho epistemológico, mas também e, principalmente, a fórmula de reconhecimento do contexto real em que as conquistas teóricas da doutrina poderão ser vivenciadas.

Para Häberle (2003), a comparação jurídica deve ser praticada como comparação de culturas:

Sin importar lo que se piense de la sucesión de los métodos tradicionales de la interpretación, en el Estado constitucional de nuestra etapa evolutiva la comparación de los derechos fundamentales se convierte en 'quinto' e indispensable método de la interpretación. (p. 162)

Fernandéz Segado (2003), ao anotar que as reflexões científico-culturais oriundas do direito constitucional comparado podem servir, em parte, para esclarecer e justificar as diferenças e, também, para encontrar elementos comuns, observa que Häberle acredita que o comparativismo constitucional pode produzir frutos imensuráveis tanto no plano da exegese, das modificações pela interpretação, quanto na própria realidade circundante da Constituição. Segado registra que, dessa forma, o direito comparado de cunho científico-cultural se revela especialmente adequado na seara das políticas legislativa e constitucional, apresentando-se também como de grande utilidade no âmbito da simples interpretação do direito constitucional vigente (direito positivo).

É preciso ter em mente que a expressão direito comparado se refere, antes de tudo, a um modo de conceber o direito como experiência real baseada na consideração de suas possíveis alternativas, destacando uma atenção mais incisiva à historicidade de toda a construção do pensamento jurídico. Por outro lado, não se trata de estabelecer afinidades ideológicas entre ordenamentos constitucionais, mas sim de utilizar o método comparado para iluminar o significado valorativo dos diversos modelos institucionais, sem pretender anular a diversidade cultural entre os países. Pela teoria da cultura, é fundamental que se volte a uma comparação valorativa entre institutos, instrumentos conceituais, modelos de solução de controvérsias jurídicas, restabelecendo a exigência de um rigoroso estudo comparado dos diversos ordenamentos jurídicos, com o fim de aprofundar o significado da diversidade e das orientações valorativas. É útil a esse propósito realçar que o direito constitucional do nosso tempo tem, antes de tudo, a necessidade de manter abertas as expectativas que nutrem o próprio direito desde a Revolução Francesa: esperança, tolerância e responsabilidade (HÄBERLE, 1998).

Considerada a definição de Häberle de Constituição como espelho da herança cultural de um povo e fundamento de esperanças, ela pode representar um bom ponto de partida para a reflexão sobre a utilização do método comparado no direito 
constitucional, já que pressupõe a renúncia a qualquer pretensão de imposição de uma única doutrina científica sobre a disciplina. Com base nisso, o jurista alemão ressalta que a amplitude dos direitos fundamentais não depende tanto dos enunciados textuais quanto do seu sucessivo desenvolvimento, indicando que os caminhos para a ampliação da tutela dos mesmos podem se dividir em uma via de ampliação da comparação no interior do próprio ordenamento e em outra na qual a comparação se volta à variedade dos exemplos dos demais Estados constitucionais.

A exigência de ter em conta métodos de estudo mais abertos e fundados no recurso à comparação de ordenamentos jurídicos se desenvolve sobre planos diferentes daquele de tipo lógico-dedutivo, já que a mesma ideia de comparação exclui a simplificação e a eliminação da diversidade, com também exclui a utilização de esquemas universais ou métodos formalistas no estudo do direito. Excluída está a adoção de qualquer dogma jurídico como absoluto e incontroverso, restando fundado o método comparativo na exigência de concretização que necessariamente o deve inspirar.

Comum a todos os Estados constitucionais, o tema dos direitos fundamentais postula uma identificação de tais direitos, o que constitui uma atividade cognitiva que repousa eminentemente nos juízes nacionais, realidade que só aumenta a utilidade dos estudos comparados para esses, não somente sobre os modelos argumentativos e sobre as categorias conceituais utilizadas pela jurisprudência, mas também para facilitar a percepção das diversas culturas jurídicas e antropológicas implicadas em cada um dos modelos de tutela dos direitos fundamentais.

Não se pode perder de vista que a consagração da comparação jurídica como quinto método de interpretação no contexto do Estado constitucional se revela como uma consequência histórica da própria doutrina da interpretação jurídica. Isso porque, se na Escola Histórica de Savigny era natural que o método histórico de interpretação tivesse lugar de destaque, da mesma forma se apresenta lógico que, no paradigma de uma teoria do Estado constitucional, o método comparativo se revele proeminente, considerando que ele constitui a via pela qual as diversas Constituições nacionais podem comunicar entre si, enriquecendo-se mutuamente e aumentando o leque de vias interpretativas.

Por fim, é importante registrar que o método comparativo, proposto como caminho metodológico adequado para a concretização das Constituições neste século recém iniciado, não implica em desconsideração das peculiaridades nacionais, em prol de uma ordem universal, mas exige a busca constante, de maneira aberta e sensível, do particular e do individual em contraponto com o paradigma do "outro". O que fica dessa lição é que o excesso, a favor ou adversariamente à comparação jurídica, pode afastar o magistrado da conjuntura social, econômica e cultural em que se insere o dilema jurídico-constitucional em julgamento, evidenciando, com isso, a possibilidade de decisões "ruins" também sob o pálio da comparação. 
Conclui-se, portanto, que a proposta häberliana de estudar mais a fundo o direito constitucional, fazendo referência aos seus contextos culturais, é de grande interesse para todos os juristas, indo ao encontro do Estado constitucional cultural. Da mesma forma, a proposta favorece o pensamento das possibilidades, a visão do outro, sendo importante frisar que, a partir de uma perspectiva comparada no ato interpretativo, os textos constitucionais poderão prover normas para a esperança, assegurando espaços para a tolerância, para as alternativas e para o pluralismo.

\section{CONSIDERAÇÕES FINAIS}

Apesar de a termos construído de uma forma nitidamente resumida e sem qualquer pretensão de sistematização, ${ }^{44}$ entendemos que a exposição evidenciou o amplo respaldo de que goza a comparação jurídica na racionalidade das Cortes daqueles países unidos por um conceito ocidental de Constituição (SOARES, 1988). É necessário frisar que a realidade não se resume ao apresentado aqui, sendo experimentada em muitos outros tribunais que têm a função precípua de zelar pela ordem constitucional. ${ }^{45}$

Dos casos analisados, conclui-se que a comparação de direitos é muito mais utilizada e melhor trabalhada pelos tribunais português e sul-africano em relação ao que se constata da realidade brasileira e, em nível ainda maior, dos Estados Unidos, mas isso não retira qualquer valor à comparação jurídica e cultural para a evolução constitucional em tempos de Estado constitucional, comum a todos esses países.

No Brasil e nos Estados Unidos, o argumento comparado é, consoante os casos analisados, inservível a qualquer pretensão de vinculação da ratio decidendi, sendo manejado apenas no nível de obter dictum, ou seja, constitui-se em um valioso reforço, mas complementar ou retórico. Portanto, o produto da comparação não perfaz o argumento nuclear da decisão. Ainda assim, a comparação tem altíssimo valor para a tarefa inesgotável de abertura do espírito a novas culturas e de expansão do horizonte cultural dos juízes, bem como para manter a abertura das possibilidades interpretativas da norma constitucional, fornecendo meios para sua própria evolução, o que permite concluir que, ainda que o juiz encontre inspiração no direito estrangeiro, no Brasil as razões persuasivas continuam atadas a fontes domésticas, de maneira que os argumentos provenientes da comparação influenciam a interpretação da lei constitucional, mas não de maneira a serem valorados como verdadeiramente decisivos para concretização da Constituição no âmbito judicial.

Quando manejado sabiamente pelas Cortes constitucionais, o argumento comparado põe-se em confronto com a realidade própria de cada país, mesmo no caso em que o direito estrangeiro detém supedâneo normativo para servir à interpretação/aplicação dos direitos fundamentais, como no caso sul-africano. Apesar disso, vimos como o recurso à comparação é mal visto nos Estados Unidos, enquanto nos 
demais contextos, até mesmo no Brasil, os cultores da ciência jurídica parecem não se opor ao seu uso.

É certo também que o desenvolvimento dos meios de comunicação, trazendo consigo o rápido acesso a sentenças estrangeiras pela rede mundial de computadores, inclusive com mecanismos de pesquisa, facilitou sobremaneira a possibilidade de acesso a tais decisões, fazendo possível a elevação do número de casos e direitos estrangeiros trabalhados nas decisões dos tribunais. O amplo e cada vez mais considerável uso do argumento comparado pelos tribunais constitucionais dos países ao redor do mundo parece ser corolário do Estado constitucional cultural, forma de Estado que - em sequência natural do Estado de Direito e do Estado Social - emerge primeiramente no âmbito da experiência constitucional europeia no período do pós-guerra e se afirma em um contexto que conduz ao nascimento, em sucessão temporal, depois de 1945, das Constituições francesa, italiana, alemã, portuguesa, espanhola e, mais recentemente, de vários países do leste europeu, sendo que todas essas se juntam às de outros países, a exemplo da Constituição norte-americana e da brasileira, assinalando uma conotação comum, segundo um modelo pautado no liberalismo democrático, na tutela dos direitos fundamentais e da liberdade.

Nesta senda, a comparação jurídica e cultural em tempos de Estado constitucional serve para "abrir a mente e o espírito" e o horizonte cultural do magistrado encarregado de zelar pela Constituição, bem como para franquear a abertura das possibilidades de interpretação e aplicação da norma constitucional, fornecendo meios para sua própria evolução. Importante também é a consideração da tendência de que nesse tipo de Estado constitucional certos valores, particularmente no campo dos direitos humanos, têm se afirmado em nível transnacional, quando não global. Nesse sentido, a comparação operada pela jurisdição constitucional contribui muito para o fenômeno da extensão e da uniformização da garantia dos direitos fundamentais, e, ainda que a comparação forneça parâmetros para aprofundar os argumentos trabalhados em um determinado tipo de conflito de direitos fundamentais, que muitas vezes são comuns à sociedade ocidental como um todo, é prematuro afirmar que haja, neste momento, tendência à convergência jurisprudencial.

Enfim, vimos como é exigível do jurista de hoje um esforço - consciente - de compreensão das possibilidades fornecidas pela comparação jurídica, o que ilide qualquer tentativa desavisada de querer "parar o vento com as mãos" e negar a importância dela para a própria evolução constitucional. 


\section{NOTAS}

1 À exceção do Supremo Tribunal Federal, em relação ao qual a pesquisa concentrou-se no seu sítio virtual na rede mundial de computadores, haja vista a tentativa, sem sucesso, de encontrar discussões mais desenvolvidas em textos científicos, em todos os demais tribunais abordados neste estudo as decisões analisadas foram obtidas com apoio na doutrina, nomeadamente a obra coletiva Corti nazionali e comparazione giuridica, de Ferrari e Gambaro, a qual serviu também de estímulo científico para aproximar o temário da comparação de direitos à realidade brasileira.

2 Não se trata, como visto, de uma abordagem àquilo que a comparação fornece como metodologia de estudo da disciplina direito constitucional, inquestionavelmente importante e frutífera, mas sim no que propõe - e nas dúvidas que alimenta - em relação à aplicação de decisões e outros juízos às decisões judiciais dos Tribunais constitucionais.

3 É preciso reconhecer a histórica problemática acerca da denominação desse ramo do saber jurídico. Neste estudo, adota-se a expressão direito comparado, sem prejuízo do uso de outras ao longo do texto e sem a intenção de tomar partido da discussão que há tempos ocupa os cultores da comparação jurídica, tal como relatado no estudo de Dantas (1997).

4 Está registrado na obra histórica de Sarfatti (1945, p. 215) o objetivo do direito comparado voltado para a unificação internacional do direito privado. No mesmo sentido, Dantas (1997, p. 243 e s.) mostra que a preocupação com a unificação do direito era frequente na discussão dos comparativistas no tocante à função da disciplina.

5 Dantas (1997, p. 242) acompanha Caio Mário da Silva Pereira para afirmar que o direito comparado não é somente um método, mas ciência.

6 Miranda (2002, p. 651) ensina que "uma clara consciência do interesse ou do interesse específico da interpretação constitucional não surgiu (como não surgiria acerca de outras questões) durante a maior parte do século XX. Apareceu mais tarde, quando [...] se avançou no esforço de construção dogmática dos sistemas constitucionais”.

7 Todos esses países conectam-se ao “conceito ocidental de Constituição" (SOARES, 1986), resultado da evolução de uma concepção - ainda que meramente ideal, o que não significa desprestígio à sua função paradigmática - de "Constituição moderna", cujas dimensões fundamentais incorporam a) a ordenação jurídico-política plasmada num documento escrito; b) declaração, nessa carta escrita, de um conjunto de direitos fundamentais e suas garantias; c) organização do poder de forma a limitá-lo e moderá-lo. A recolha dos ordenamentos jurídicos deste estudo, apesar de denotar certa aleatoriedade, seguiu limitada por essa concepção paradigma. Além disso, também contribuíram o recente destaque conferido pela doutrina ao texto constitucional sul-africano, a notória importância do constitucionalismo norteamericano e a aproximação científica do autor à ciência jurídico-constitucional lusitana.

8 Aprovada a Lei do Tribunal Constitucional, Lei n ${ }^{\circ}$ 28/82, somente em 31 de maio de 1982 ano que o Tribunal viria a proferir o seu primeiro acórdão.

9 Influenciado pelos estudos da doutrina portuguesa, que sempre se manteve atenta aos desenvolvimentos científicos e doutrinários das principais tradições jurídicas ocidentais, bem como pela própria origem acadêmica de grande parte dos juízes constitucionais.

10 Cfr. Romano Orrú (2006, p. 11), esse ordenamento é visto como "poroso e particularmente exposto aos influxos externos".

11 O artigo 16, item 2, da Constituição da República Portuguesa afirma que: "Os preceitos constitucionais e legais relativos aos direitos fundamentais devem ser interpretados e integrados de harmonia com a Declaração Universal dos Direitos do Homem". No nosso entender, tal exigência demonstra a abertura do Estado português à comparação, mas não importa na consideração obrigatória desta como um dos seus pressupostos. Também neste aspecto cumpre assinalar que o Código Civil português, em seu artigo $9^{\circ}$, reproduz preceito atinente à interpretação da lei voltado somente à busca do pensamento legislativo.

12 Orrú (2006, p. 22 e s.) avalia o modus procedendi dos juízes portugueses no trato do argumento comparado. Algumas vezes a atenção ao direito comparado se manifesta de forma fugaz e sumária (mera citação), outras de modo analítico (a fim de explicar os possíveis inputs judiciário, normativo e doutrinário, a exemplo do Acórdão nº 288/98, ou 
quando a maior parte da motivação vem explicitamente composta pelo Direito comparado, como o Acórdão n ${ }^{\circ} 479 / 94$ ). Às vezes, há um manejo mais cuidadoso do TCP, a partir da seleção de elementos externos com quadro constitucional semelhante ao português. Há casos em que o TCP não demonstra muita exigência técnica, tal como no Acórdão n ${ }^{\circ}$ 589/04, no qual, sem a mínima prudência classificatória ou justificação teórica, mencionou normas da Carta canadense, da Espanha, Rússia, Bolívia, Itália, Brasil, Chile, Bélgica e Finlândia (ORRÚ, 2006, p. 24-5) acerca da liberdade de associação.

13 É o que se confirma a partir da transcrição de parte do acórdão Acórdão n 121/79, p. 12: “tendo presente os dados doutrinais e de direito comparado carreados para os autos, importa decidir a questão de constitucionalidade suscitada pelo recorrente".

14 Acórdão nº 301/06.

15 É o que se verifica da leitura do Acórdão no 607/03, verbis: “Considera-se não ser despiciendo dedicar alguma atenção ao tratamento jurisprudencial e dogmático que os casos diários mereceram na Alemanha, referindo-se em particular a discussão do problema no âmbito da jurisdição constitucional germânica, dado reconhecer-se, com fundamento, a 'afirmação da proximidade' ou 'a sobreposição substancial' entre o direito português e o alemão".

16 Advoga-se que a Constituições de Brasil e de Portugal dividem a mesma filosofia.

17 A verificação do uso intenso do direito internacional pelo Tribunal Constitucional português e nos demais surgiu como resultado não almejado - embora bem-vindo - da pesquisa. Com efeito, a carga normativa do Direito internacional demandaria investigação própria, muito além dos limites do presente estudo, que foi voltado à interpretação-concretização do texto constitucional mediante aplicação de um método - ou disciplina - específico, o direito comparado. Trata-se, a rigor, de campos de estudo distintos entre si, com efeitos também particulares em relação aos sistemas jurídicos.

18 Slaughter (2003, p. 199) observa que a Corte Suprema estadunidense, acostumada em ser "source" para tribunais estrangeiros, caminhou a partir da década de 1980 no sentido de se tornar também "borrower".

19521 US 898, (1997), $\mathrm{n}^{\circ} 95-1478$ e $\mathrm{n}^{\circ} 95-1503$

20 Segundo Delahunty e Yoo (2005, p. 292 e s.), o Juiz Breyer é explícito defensor do uso do direito estrangeiro, assim como os juízes Stevens, O'Connor e Ginsburg.

21 A teorização se deve a Sheppele (2003), no estudo acerca das influências constitucionais cruzadas a partir de modelos negativos.

2273 USLW 4.153 (2005), nº 03-633.

23 Em primeiro lugar, a "Reaffirmation of American Independence Act" (H.R.Res. 97, 109th Congr. 2005) e depois o projeto denominado "Constituition Restoration Act” (S.520, 109th Congr. 2005 e H.R. 1070, 109th Congr. 2005), este último prevendo até o impeachment no caso de descumprimento.

24 "When interpretating the Bill of Rights, a court, tribunal or forum: (a) must promote the values that underlie an open and democratic society based on human dignity, equality and freedom; (b) must considerer international law; and (c) may consider foreign law."

25 Decidiu-se que o ônus da prova seria da acusação, e não do acusado, tendo o Tribunal observado que a jurisprudência colacionada à decisão, oriunda da Corte Suprema dos Estados Unidos, da Corte canadense, do Tribunal Europeu dos Direitos Humanos, entre outros, provém de tribunais de sociedades abertas e democráticas e estava a indicar que o ônus reverso no caso debatido não era de forma alguma incomum e não era, necessariamente, inconstitucional.

26 Rinella (2006, p. 401) observa que no caso “Zuma versus Estado" pode ter havido uma certa vinculação, mas isso não se constituiu em tendência no Tribunal sul-africano.

27 A superação do período de déficit democrático trouxe consigo a dúvida acerca da capacidade dos magistrados de assimilarem prosperamente o cumprimento da nova cultura constitucional, o que também foi sentido em Itália, Portugal, Alemanha, entre outros países, suscitando, por exemplo, o tema da "Constituição não atuada". 
28 Observa Rinella (2006) que o objetivo do Tribunal não é imitar um modelo estrangeiro de proteção dos direitos fundamentais, mas fomentar a construção de uma democracia em que os valores constitucionais são estabelecidos e interpretados à luz do seu peculiar sistema jurídico, da história e das condições sociais que constituem o pano de fundo da Constituição da África do Sul e que devem ser constantemente mantidos em conta pelo mesmo.

29 Segundo Rinella (2006), muitos dos juízes que já passaram pelos quadros judicantes da Corte sul-africana completaram seus períodos de estudo jurídico em universidades de outros países, além de participações em seminários e outros eventos que facilitaram a ocorrência da aludida "attrezzatura culturale".

30 A recolha dos julgados que substancializaram a presente análise foi feita através da rede mundial de computadores no sítio do próprio Tribunal. A pesquisa, realizada no mês de janeiro de 2010, teve como parâmetro as seguintes expressões completas e entre aspas: "direito comparado" (sessenta resultados), "argumento comparado" (nenhum resultado), "comparação jurídica" (nenhum resultado), "comparação de/entre direitos" (nenhum resultado) e "direito estrangeiro" (oito resultados). Além disso, foram compulsados os votos e acórdãos dos casos mais polêmicos julgados recentemente pelo STF.

31 A análise quantitativa do resultado da pesquisa indica que são esses os magistrados em exercício que mais comumente fazem uso da comparação em seus votos. É interessante perceber que a atenção constante à comparação entre direitos parece se conectar às respectivas formações acadêmicas dos magistrados, uma vez que todos os ministros mencionados como mais afeitos à comparação têm anotados em seus currículos publicados no sítio do Tribunal momentos de vivência cultural e jurídica em outros países.

32 Destaca-se entre os resultados da consulta textual ao sítio do STF o grande emprego da comparação no julgamento de ações diretas de inconstitucionalidade, as quais representam cerca de $40 \%$ dos casos apurados, seguido pelas questões de ordem em ação penal, Habeas Corpus, mandados de injunção e outros.

33 A decisão mais antiga apurada pela pesquisa foi julgada em 1977, pelo então ministro Dajci Falcão, a propósito de um pedido de extradição formulado pelo Governo Suíço contra Raphael Patrola (Pedido de Extradição no ${ }^{\circ 36}$ ). Por outro veio, a maioria das ementas respondidas pela pesquisa textual datam de 1999 em diante e abordam os casos mais polêmicos decididos pelo STF, a exemplo da questão dos fetos anencéfalos, poderes da fiscalização tributária e policial em cotejo com os direitos e as garantias individuais e, mais recentemente, o julgamento da ação popular sobre a demarcação da terra indígena Raposa Serra do Sol, julgado em 19/03/2009

34 Mandado de Injunção nº 708/DF, julgado em 25/10/2007.

35 Habeas Corpus $\mathrm{n}^{\circ}$ 82424/RS, julgado em 17/09/2003.

36 Entre outros motivos, a citação dos referidos elementos do direito estrangeiro serviu para a conclusão de que o conceito de racismo previsto na Constituição Federal de 1988 contempla a prática de antissemitismo, conclusão essa estampada no voto-vista do ministro Gilmar Mendes. É provável que tenha sido este o caso em que o elemento comparado se fez mais presente na história constitucional brasileira recente.

37 Todas as decisões indexadas pela instituição e publicadas no sítio virtual são acompanhadas de um campo específico junto à ementa denominado "doutrina", no qual são citadas as obras científicas que confluíram para o julgamento. Esse instrumento, além de haver tornado menos árdua tanto a pesquisa quanto a apuração dos resultados, permitiu obter um resultado quantitativo acerca da origem dos estudos sobre os vários direitos "nacionais" que mais marcadamente assomam para as decisões da Corte brasileira.

38 Qualitativamente, a análise dos textos suscitados nos julgamentos dos ministros brasileiros demonstra que a maioria das citações se refere a obras que abordam a problemática dos direitos fundamentais e, em maior parte, sobre a Teoria da Constituição, além de obras sobre teorias gerais do direito e direito penal.

39 Häberle (2003, p. 125) fala em equilíbrio, no tempo, entre continuidade e mudança, entre estabilidade e flexibilidade, a permitir a conservação do Estado constitucional no curso temporal.

40 Pensamos também na revisão das funções da Constituição realçada por Canotilho (2003, p. 1.450), mirando a função de inclusividade multicultural no bojo de uma sociedade multicultural. 
41 Tradução livre: "Não existe norma jurídica senão norma jurídica interpretada".

42 É importante destacar que até a noção do que é clássico é relativizada na sociedade aberta de intérpretes: “Nosotros somos el sujeto de referencia de los clásicos” (HÄBERLE, 2003, p. 48).

43 Termo do idioma espanhol. Em tradução livre: aspas.

44 Referimo-nos ao exame por nós levado a efeito da jurisprudência do STF que transcorreu apenas para fins demonstrativos de uma tendência.

45 Vide FERRARI e GAMBARO, Corti nazionali e comparazione giuridica (Roma: Edizioni Scientifiche Italiane, 2006).

\section{REFERÊNCIAS BIBLIOGRÁFICAS}

ACKERMAN, Bruce. The Rise of World Constitutionalism. Virginia Law Review, v. 83, n. 4, maio 1997, p. 771-97. CANOTILHO, José Joaquim Gomes. Direito Constitucional e Teoria da Constituição. 7. ed., 2. reimpressão. Coimbra: Almedina, 2003.

COELHO, Inocêncio Mártires. Konrad Hesse/Peter Häberle: um retorno aos fatores reais do poder. Revista de Informação Legislativa, v. 35, n. 138, abr-jun 1998, p. 185-91.

DANTAS, Ivo. Direito Comparado como Ciência. Revista de Informação Legislativa, v. 34, n. 134, abr-jun 1997, p. 231-249.

DAVID, René. Os grandes sistemas do direito contemporâneo. São Paulo: Martins Fontes, 1989.

DELAHUNTY, Robert J.; YOO, John. Against Foreign Law. Harvard Journal of Law \& Public Policy, v. 29, n. 1, 2005, p. 291-330.

FERNÁNDEZ SEGADO, Francisco. In: HÄBERLE, Peter. La garantía del contenido esencial de los derechos fundamentales. Tradução de Joaquín Brage Camazano. Madri: Dykinson, 2003.

FERRARI, Giuseppe Franco. La comparazione giuridica nella giurisprudenza della Corte suprema degli Stati Uniti d'America. In: FERRARI, Giuseppe Franco; GAMBARO, Antonio (Orgs.). Corti nazionali e comparazione giuridica. Roma: Edizioni Scientifiche Italiane, 2006.

HÄBERLE, Peter. El Estado constitucional. Tradução de Hector Fix-Fierro. México: Universidad Nacional Autônoma de México, 2003.

. Libertad, igualdad, fraternidad: 1789 como historia, actualidad y futuro del Estado constitucional. Madri: Minima Trotta, 1998

. Teoria de la Constitución como ciencia de la cultura. Tradução de Emilio Mikunda. Madri: Tecnos, 2000.

$\mathrm{KOH}$, Harold H. International Law as part of our Law. The American Journal of International Law, v. 98, n. 1, jan. 2004, pp. $43-57$.

LUCAS VERDÚ, Pablo. Teoria de la constitución como ciencia cultural. 2. ed. Madri: Dykinson, 1998.

MAXIMILIANO, Carlos. Hermenêutica e aplicação do direito. 19. ed. Rio de Janeiro: Forense, 2003.

MIRANDA, Jorge. Teoria do Estado e da Constituição. Coimbra: Coimbra Editora, 2002.

MENDES, Gilmar Ferreira. O pensamento de Peter Häberle na jurisprudência do Supremo Tribunal Federal. Observatório da Jurisdição Constitucional. Ano 2. Brasília: IDP, 2008/2009. Disponível em:

<http://www.conjur.com.br/2009-abr-10/pensamento-peter-haberle-jurisprudencia-supremo-tribunalfederal>. Acesso em: 15 dez. 2009.

MENDES, Gilmar Ferreira. La construcción de un derecho común iberoamericano. Consideraciones en homenaje a la doctrina de Peter Häberle y su influencia en Brasil. Revista de Derecho Constitucional Europeo, ano 6, n. 11, jan.-jun. 2009, pp. 65-86.

ORRÚ, Romano. La giustizia costituzionale e il paradigma comparato: l'esperienza portoghese. In: FERRARI, Giuseppe Franco; GAMBARO, Antonio (Orgs.). Corti nazionali e comparazione giuridica. Roma: Edizioni Scientifiche Italiane, 2006.

RINELLA, Angelo. La Corte costituzionale del Sudafrica: il contributo del diritto comparato al consolidamento della democrazia. FERRARI, Giuseppe Franco; GAMBARO, Antonio (Orgs.). Corti nazionali e comparazione giuridica. Roma: Edizioni Scientifiche Italiane, 2006.

SACCO, Rodolfo. Introdução ao Direito Comparado. São Paulo: RT, 2001. 
SARFATTI, Mario. Introducción al estudio del Derecho Comparado. México: Imprenta Universitaria, 1945. SHEPPELE, Kim Lane. Aspirational and Aversive Constitutionalism: The Case for Studing Cross-constitutional Influence through Negative Models. ICON, v. 296, n. 1, 2003.

SLAUGHTER, Anne-Marie. A Global Community of Courts. Harvard International Law Journal, v. 44, n. 1, 2003, p. 191-220.

SOARES, Rogério Ehrhardt. O Conceito Ocidental de Constituição. Revista de Legislação e Jurisprudência, Coimbra, n. 119, 1986.

TUSHNET, Mark. The Possibilities of Comparative Constitutional Law. Yale Law Journal, v. 108, n. 6, abr. 1999, pp. $1225-1309$.

VALADÉS, Diego. Prólogo. In: HÄBERLE, Peter. El Estado constitucional. Tradução de Hector Fix-Fierro. México: Universidad Nacional Autônoma de México, 2003.

ZAGREBELSKY, Gustavo. Stato costituzionale. In: VALADÉS, Diego; CARBONELL, Miguel (Coords.). El Estado constitucional contemporáneo. Culturas y sistemas jurídicos comparados. Tomo 2. Cidade do México: Instituto de Investigaciones Jurídicas, 2006.

\section{Gustavo Vitorino Cardoso}

Avenida Brasil, n. 3460 Bairro Brasil - 38400-718 Uberlândia - MG - Brasil gvc.pesquisalagmail.com
Mestrando em DIREITO CONSTITUCIONAL NA Faculdade de DiReito da Universidade dE CoImbra 